\title{
Dewatering as a primary treatment of faecal sludge in individual residential sector (a technologies review)
}

\author{
Alena Basamykina $^{1}$, Marianna Kharlamova ${ }^{1}$, and Sharon Yeukai Mada ${ }^{2}$ \\ ${ }^{1}$ Peoples' Friendship University of Russia (RUDN University), Faculty of Ecology, 6 Miklukho- \\ Maklaya St, Moscow, 117198, Russian Federation \\ ${ }^{2}$ The Catholic University of Zimbabwe, Faculty of Humanities and Social Sciences, 18443 \\ Cranborne Ave, Harare, Zimbabwe
}

\begin{abstract}
Dewatering of faecal sludge (FS) is the most efficient method of pretreatment of bioorganic human waste for minimizing the faecal sludge volume. This process may be considered as one of management tool in service chain of Faecal Sludge Management (FSM). For this purpose technological features of methods, the advantages, disadvantages and possibilities of the use have been analysed. The article provides a review of the most efficiently methods of faecal sludge dewatering generated in the individual residential sector (unplanted drying beds, planted drying beds, solar drying, mechanical dewatering, geotubes) and their analysis in order to select the best available technology in accordance with the selection criteria. We used the analytic hierarchy process to determine the most multi-operated and effective processing method of faecal sludge dewatering. The final ranking for each dewatering technology was based on the global weights of 10 criteria (dewatering efficiency, operation time, process automation, required space, climate dependent, capital expenditures, operating costs, energy efficiency and environmental impact). The results identify dewatering method with the highest priority result based on priority eigenvalues of criteria.
\end{abstract}

\section{Introduction}

Faecal sludge (FS) generated in the individual residential sector is a natural product of human activity. It is highly concentrated mixture of natural organic matter of various compositions and is very different from municipal wastewater. Due to the high variability of the organic matter composition, the design of the processing system should not be based on standard characteristics, but on the results of laboratory tests obtained for each case $[1,2,3,4]$.

Nowadays, there is much tension around the issue of collection, storage, treatment and disposal of faecal sludge in the individual residential sector in the Russian Federation. At the federal, regional and municipal levels, there is no adequate regulatory system and management of such waste type. In most cases authorities try to solve the problem at the local level, involving private companies for collecting and transporting of faecal sludge only if

\footnotetext{
*Corresponding author: alena.basamykina@gmail.com
} 
owner pays for this service. Moreover, the collected faecal sludge is discharged to sewage treatment plants or worse to a water body or on the ground. Thus, enormous damage is caused to the environment that, at the moment, cannot be estimated due to the lack of a monitoring system $[1,5,6]$.

To solve this problem, an integrated approach is required. It should include not only the implementation of planning and management systems, but also the applicability of the resource potential of faecal sludge using the best available technologies. From an economic feasibility point of view, the most important problem is the reducing of transportation costs. With this objective in view, the use of small semi-centralized plants for the primary processing of faecal sludge generated in the individual residential sector allows to minimize the FS volume and transportation costs $[1,5]$. Faecal sludge co-treatment with wastewater is possible to optimize the technological process of FS treatment $[4,7,8]$.

The most efficient method for minimizing the faecal sludge volume is dewatering. This process leads to a decrease of the moisture content from $98 \%$ to $75 \%$ (that is tantamount to an increase of the solids content from $2 \%$ to $25 \%$ ). Moreover, the volume of dewatered faecal sludge that must be transported for another treatment step will be 12 times less than the unprocessed volume. That can significantly reduce transportation costs. [1,6]

This article analyzes the most common methods of faecal sludge dewatering, and also makes a criteria comparative analysis to determine the most multi-operated and effective processing method.

\section{Materials and methods}

\subsection{The analytic hierarchy process (AHP)}

In this article we used the analytic hierarchy process to conduct criteria evaluation to determine the most multi-operated and effective dewatering method of faecal sludge.

The analytic hierarchy process (AHP) is a mathematical structured technique for complex decisions. The method does not imply any "correct" solution, but allows interactively finding the best decision consistent with the given problem essence and the requirements for its solution. The analytic hierarchy process is used to compare objects, to solve management problems, forecasting, etc [9].

The AHP generates a weight for each evaluation criterion (dewatering efficiency, operation time, process automation, required space, climate dependent, capital expenditures, operating costs, energy efficiency, emissions and process waste). The higher the weight, the more important the corresponding criterion. Next, for a fixed criterion, the AHP assigns a score to each dewatering methods (unplanted drying beds, planted drying beds, solar drying, mechanical dewatering, geotubes) The higher the score, the better the performance of the option with respect to the considered criterion. Finally, the AHP combines the criteria weights and the dewatering methods scores, thus determining a global score for each method, and a consequent ranking. The global score for a given dewatering method is a weighted sum of the scores it obtained with respect to all the criteria [9].

Each criterion is expressed by an attribute. The larger the value of the attribute, the better the performance of the dewatering method with respect to the corresponding criterion. 


\subsection{Dewatering methods}

\subsubsection{Unplanted drying beds}

Unplanted drying bed is a permeable layer where faecal sludge is dried by natural evaporation. The site is filled with filter media, most commonly gravel is a bottom layer and sand is a upper layer (Fig. 1). The bottom has a slope where the drainage system is located $[4,6,10]$.

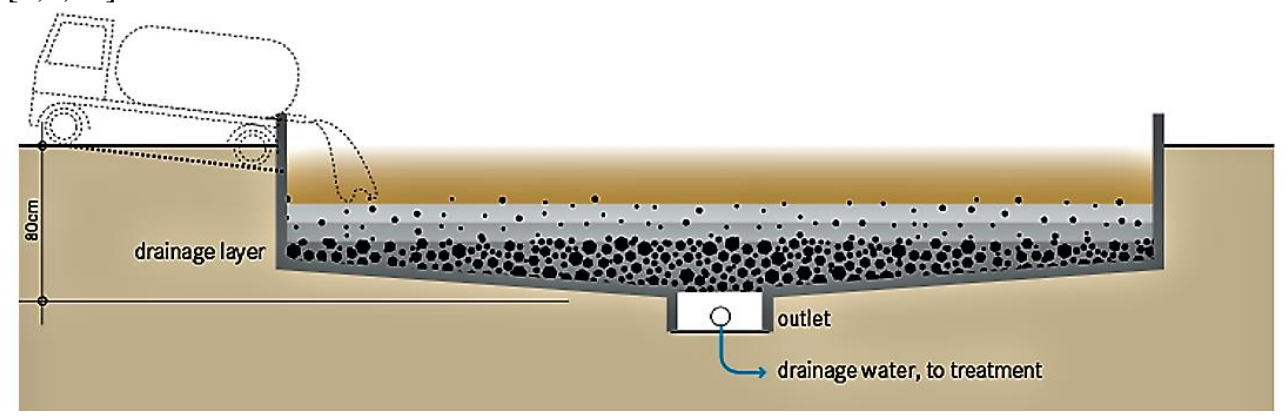

Figure 1. Schematic of an unplanted drying bed [11]

Unplanted dying beds are operated in periodic mode. Faecal sludge is located on the surface, liquid infiltrates through sand and gravel for several days. The bulk of solid fraction remains on the surface. Approximately 50-80\% of faecal sludge (volume) infiltrates as liquid through the filter media or evaporates. Hence, dehydrated faecal sludge is removed from the surface manually (by shovels) or mechanically (by scraper system or equipment), once every few weeks or months depending on operating conditions [6, 8,10,12].

There is a disadvantage of this technology -regularly the filter media treatment before a new process cycle. Moreover, faecal sludge has no effective stabilization or disinfection $[6,12]$.

Unplanted drying bed should have tent covers or roofs to protect from rain, otherwise the dewatering process will be ineffective $[6,8]$.

\subsubsection{Planted drying beds}

The ongoing process is similar to the process occurring on a standard drying beds. But difference is that there is plants cultivation on planted drying beds (Fig. 2). Plants selected for a specific climate. Moreover, there is additional evaporation and more efficient faecal sludge dewatering instead of standard drying beds. The filter material does not need to be cleaned after each feeding/ drying cycle $[6,7,8]$.

Planted drying bed must be acclimatized oneself for at least three months before faecal sludge loading. Raw material can be laid directly on the previous layer. Plants and their root systems maintain the filter porosity. They must be collected from the site in accordance with the growth cycle $[4,6,8,14]$.

Studies $[8,14]$ demonstrate that plant growth accelerates with increasing loading frequency of planted drying bed. Plant growth can have a significant impact on both site performance and the potential use of end product.

Extended period of dewatering time can lead to increased inactivation of helminth eggs. Before using of faecal sludge after treated on planted drying beds in agriculture, it is necessary to realize a composting process [14]. 


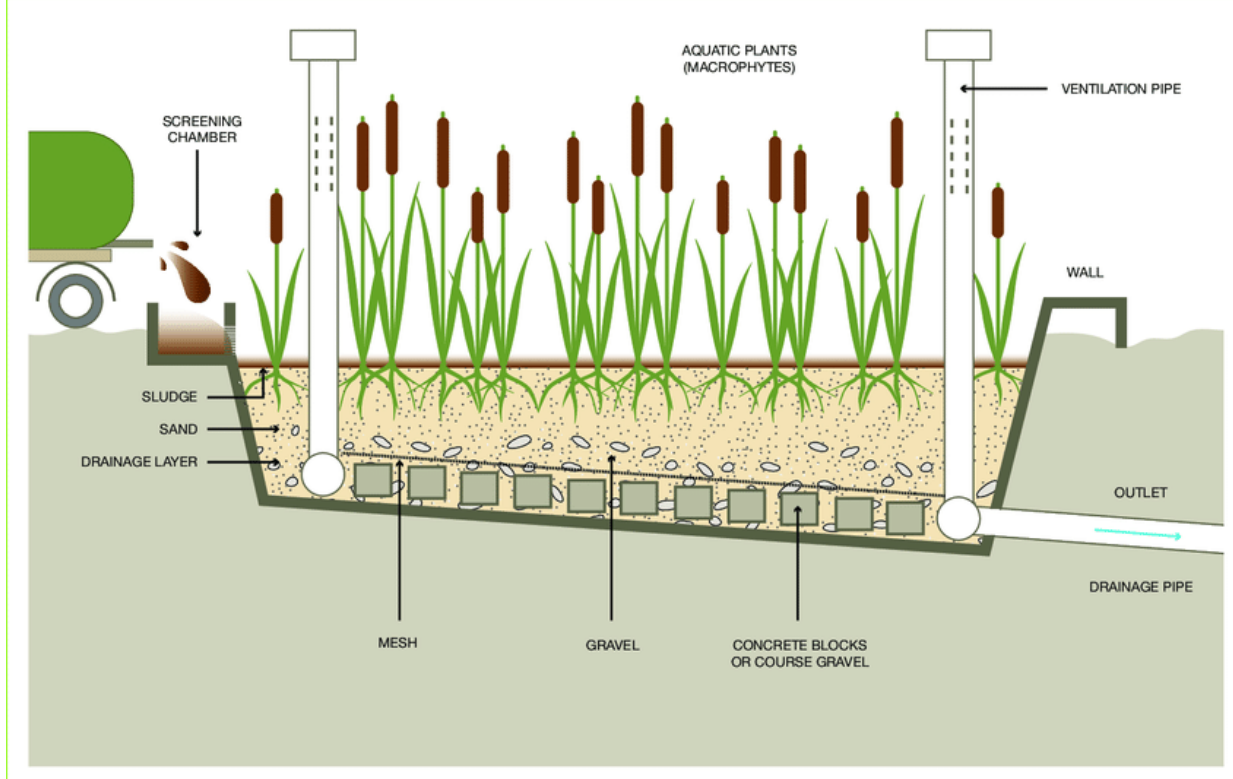

Figure 2. Schematic of a planted drying bed [13]

\subsubsection{Solar drying}

Solar drying is the process of moisture removing by means of sunlight. There is a banch process. A special textiles (geotextiles) and a perforated layer are added for dewatering between the layer of faecal sludge and sand (Fig. 3).

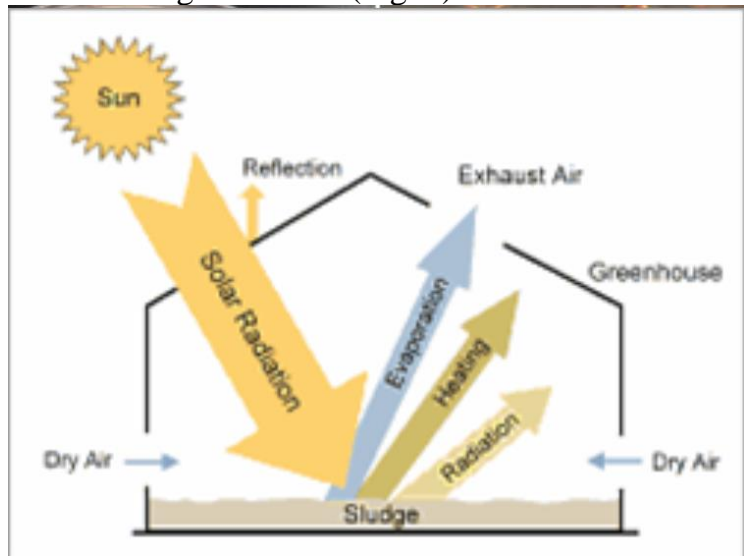

Figure 3. Solar drying process [16]

This will ensure preventing of layers mixing and improving the process efficiency of dewatering and filtration $[3,4,15]$.

The intake of rainwater can significantly reduce the rate of faecal sludge dewatering. Therefore, a transparent roof should be provided above the site for optimal removal of evaporated moisture. The roof surface must be made of durable plastic for optimizing the sunlight penetration $[3,15]$. 


\subsubsection{Mechanical dewatering}

Mechanical dewatering is usually carried out on a screw press (Fig. 4). Dewatered faecal sludge must proceed to additional stage (for example, drying or composting) before usage as organic fertilizer. Centrifuges, belt presses or filter presses may be used instead of a screw press, but this machines is less efficient $[4,7,8,17]$.

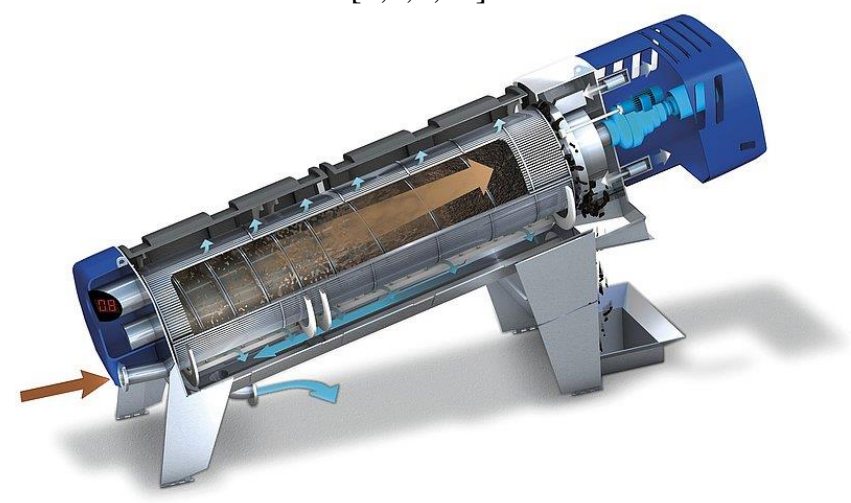

Figure 4. Screw press for sludge dewatering [17]

The main disadvantage of this method is a coagulant (polyelectrolyte) demand to stabilize the dewatering process as well as to increase its effectiveness. The results show that conditioning does not increase dewatering rate, but increases moisture reduction rates $[8,17,18,19]$.

Not only polymeric materials can be used as conditioners for faecal sludge, but also waste from local plant resources (for example, seeds, oilcake or chitosan). They are as effective as polymers for dewatering sewage sludge [18].

The $M$. Oleifera seeds, oilcake and chitosan are natural organic materials that can increase the useful properties of the end processed products, such as nutrient content $(\mathrm{C}, \mathrm{N}, \mathrm{P})$ and / or calorific value while inorganic polymers reduce the calorific value and fuel potential $[18,20]$.

\subsubsection{Geotubes}

Geotubes are highly effective because of they capture up to $98 \%$ solids. Geotextile is a permeable textile made of polyethylene fiber. It has capability to infiltrate moisture and, thus, dewatering process of faecal sludge is more effective that proceeding on drying beds. The filtrate is collected and purified. The process proceeds inadvertently, under the gravity, has no mechanical parts, and it is noiseless (Fig. 5). Therefore method is potentially suitable for decentralized FS processing. Additional external heat accelerates the faecal sludge dewatering $[6,7,8,22,23]$.
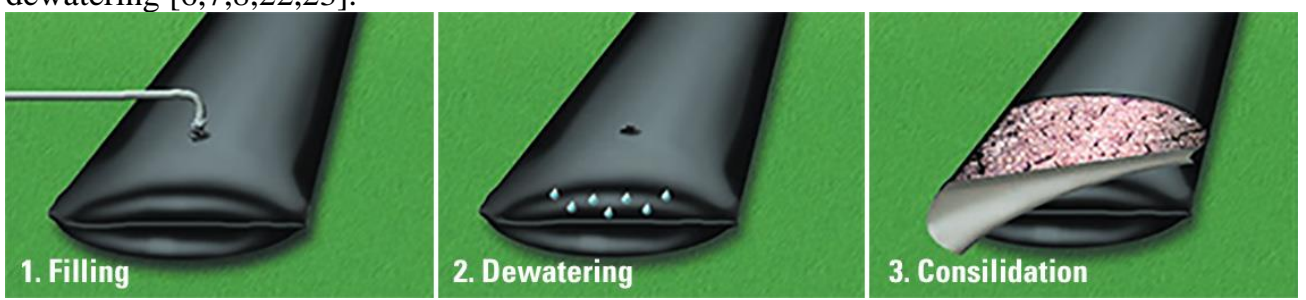

Figure 5. Dewatering with geotube technology [21]. 
A polymer is added to faecal sludge to precipitation increase and avoid clogging of the geotextile layer. For this purpose, study [22] demonstrates usage of chitosan obtained from shrimp waste. It turned out to be quite effective in the dewatering of faecal sludge from septic tanks and sewage sludge, but ineffective for faecal sludge from pit latrines.

The geotubes can increase the processing intensity and reduce the required area for dewatering at treatment plants [22]. There is a disadvantage: geotubes become a waste themselves after filling the entire volume with solids [6,7,8,22].

\section{Results and discussions}

The analytic hierarchy process is associated with a consistency ratio. Assuming that there are ten criteria (dewatering efficiency, operation time, process automation, required space, climate dependent, capital expenditures, operating costs, energy efficiency, emissions and process waste) (Table 1) and five dewatering methods, the weights of the criteria are first computed through pairwise comparisons. (Table 2).

Table 1. Criteria definition

\begin{tabular}{|c|c|}
\hline $\begin{array}{l}\text { Dewatering } \\
\text { efficiency }(D E)\end{array}$ & $\begin{array}{l}\text { The maximum moisture removal from fecal sludge due to the } \\
\text { dewatering process }\end{array}$ \\
\hline $\begin{array}{l}\text { Operation time } \\
(\text { OT })\end{array}$ & Process time of dewatering \\
\hline $\begin{array}{l}\text { Process automation } \\
(P A)\end{array}$ & $\begin{array}{l}\text { Applicability of automated units for fecal sludge feeding, for } \\
\text { removing of dewatered sludge from the unit, for liquid discharge }\end{array}$ \\
\hline Required space $(R S)$ & The area required for main unit and supporting facilities \\
\hline $\begin{array}{l}\text { Climate } \\
\text { dependent }(C D)\end{array}$ & $\begin{array}{l}\text { Climate and weather effects (rain, drought, cold temperatures, } \\
\text { etc.) on the dewatering process effectiveness }\end{array}$ \\
\hline $\begin{array}{l}\text { Capital } \\
\text { expenditures }(C E)\end{array}$ & $\begin{array}{l}\text { Costs of the site construction and the purchase of equipment, } \\
\text { including supporting facilities }\end{array}$ \\
\hline $\begin{array}{l}\text { Operating } \\
\text { costs }(O C)\end{array}$ & $\begin{array}{l}\text { Costs of chemicals, purchase of plant seeds, geobags, air supply, } \\
\text { etc. }\end{array}$ \\
\hline $\begin{array}{l}\text { Energy efficiency } \\
(E E)\end{array}$ & Energy consumption of main unit and supporting facilities \\
\hline $\begin{array}{l}\text { Emissions }(E) \\
\text { and } \\
\text { Process waste } \\
(P W)\end{array}$ & $\begin{array}{l}\text { Environmental impact includes two criteria: air emissions and } \\
\text { waste generation (plant waste, used geobags, etc.). This work does } \\
\text { not consider the environmental impact of generated wastewater, } \\
\text { since most commonly they are treated at the nearest wastewater } \\
\text { treatment plant }\end{array}$ \\
\hline
\end{tabular}

The criteria must be evaluated in pairs so as to determine the relative importance between them and their relative weight to the global goal. Table 2 shows the relative weight data between the criteria that have been determined. In order to interpret and give relative weights to each criterion, it is necessary to normalize the previous comparison matrix. The normalization is made by dividing each value by the total column value (Sum). The contribution of each criterion to the organizational goal is determined by calculations made using eigenvectors. Eigenvector indicates the relative weights between each criterion. it is obtained in an approximate manner by calculating the mathematical average of all criteria.

The RI (Retention Index) is fixed and is based on the number of evaluated criteria (10), the value is 1.49 . The maximum eigenvalue $(\lambda \max )$ is calculated by summing the product of each element in the Eigenvector by the respective column total (sum) of the original comparison matrix. The Consistency Index (CI) is defined as minimum number of changes divided by the number of changes required on the parsimony score. In order to verify whether 
the consistency index (CI) is adequate, it was suggested [9] the consistency rate (CR), which is determined by the ratio between the consistency index (CI) and the random consistency index (RI). The matrix will be considered consistent if the resulting ratio is less than 0.15 $(15 \%)$.

Table 2. Evaluation of criteria eigenvectors

\begin{tabular}{|c|c|c|c|c|c|c|c|c|c|c|c|c|}
\hline & 峝 & ㅍ & 5 & $\theta$ & પ्I & $\circlearrowright$ & 떺 & $\tilde{\simeq}$ & 3 & 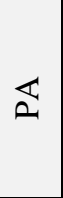 & 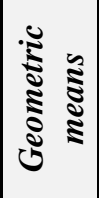 & 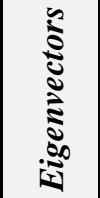 \\
\hline $\mathrm{DE}$ & 1 & 3 & 5 & 5 & 4 & 4 & 7 & 8 & 8 & 8 & 4.606 & 0.287 \\
\hline $\mathrm{E}$ & 0.33 & 1 & 3 & 5 & 6 & 7 & 7 & 8 & 8 & 9 & 3.911 & 0.244 \\
\hline OT & 0.2 & 0.33 & 1 & 2 & 4 & 5 & 5 & 7 & 7 & 8 & 2.352 & 0.147 \\
\hline $\mathrm{CD}$ & 0.2 & 0.2 & 0.5 & 1 & 2 & 3 & 3 & 4 & 5 & 7 & 1.480 & \begin{tabular}{|l|l|}
0.092 \\
\end{tabular} \\
\hline CE & 0.25 & 0.167 & 0.25 & 0.5 & 1 & 2 & 4 & 6 & 7 & 7 & 1.285 & 0.080 \\
\hline $\mathrm{OC}$ & 0.25 & 0.143 & 0.2 & 0.33 & 0.5 & 1 & 3 & 5 & 6 & 5 & 0.939 & \begin{tabular}{|l|l|} 
\\
\end{tabular} \\
\hline $\mathrm{EE}$ & 0.143 & 0.143 & 0.2 & 0.33 & 0.25 & 0.33 & 1 & 4 & 5 & 3 & 0.606 & 0.038 \\
\hline $\mathrm{RS}$ & 0.125 & 0.125 & 0.143 & 0.25 & 0.167 & 0.2 & 0.25 & 1 & 3 & 5 & 0.384 & 0.024 \\
\hline PW & 0.125 & 0.125 & 0.143 & 0.2 & 0.143 & 0.167 & 0.2 & 0.33 & 1 & 4 & 0.279 & 0.017 \\
\hline PA & 0.125 & 0.111 & 0.111 & 0.143 & 0.143 & 0.2 & 0.33 & 0.2 & 0.25 & 1 & 0.200 & 0.012 \\
\hline $\begin{array}{c}\text { Total } \\
\text { (Sum) }\end{array}$ & 2.748 & 5.344 & 10.547 & 14.753 & 18.203 & 22.897 & 30.78 & 43.53 & 50.25 & 57 & 16.042 & \\
\hline & $R I$ & 1.49 & & & & & & \multicolumn{4}{|c|}{$\lambda_{\max }$} & 11.587 \\
\hline & & & & & & & & \multicolumn{4}{|c|}{ Consistency index $(\mathrm{CI})$} & 0.176 \\
\hline & & & & & & & & \multicolumn{4}{|c|}{ Consistency rate (CR) } & 0.118 \\
\hline
\end{tabular}

Then, all of dewatering methods are pairwisely compared with respect to each criterion and set out in separate tables using the scale. The sum of each row is computed, normalised, then placed in the last column and labelled local weights. The column is used to build a new table with the criteria set out along the top row and dewatering methods build the left-hand column (Table 3). The value in each cell of each column is multiplied by the weight of the criteria associated with the columns and each of dewatering methods, and the sum of each row is computed. The computed numbers are set out in the last column of the final table, which represents the level of attention that should be paid to the alternatives or global weights. As a result, the final ranking for each dewatering technology is based on the global weights.

The Consistency Index (CI) is defined as minimum number of changes divided by the number of changes required on the parsimony score. The Consistency Rate (CR) (Table 3) is based on priority eigenvalues and the consistency index of each method. The Generalized Consistency Rate (GCR) is the ratio CR to RI. Since the Generalized Consistency Rate value (0.066) is less than 0.15 (or $15 \%$ ), the comparisons are confirmed.

Thus, using the analytic hierarchy process, we determined that mechanical dewatering is the most multi-operated and effective dewatering method of faecal sludge. Despite the low energy efficiency, significant capital expenditures and great ttechnological infrastructure, this method is most acceptable due to the best dewatering efficiency, low emissions, process automation and does not depend on climate conditions. 
Table 3. Final priority evaluation of faecal sludge dewatering methods

\begin{tabular}{|l|c|c|c|c|c|c|c|c|c|c|c|}
\hline & & & & & & & & & & & \\
\hline
\end{tabular}

\section{Conclusions}

Based on the the analytic hierarchy process to determine the most multi-operated and effective dewatering method of faecal sludge (unplanted drying beds, planted drying beds, solar drying, mechanical dewatering, geotubes), the highest priority result (3.469) was determined for the mechanical dewatering process. Principally, it is link with high dewatering efficiency, the rapid operation time, as well as the possibility of process automation and low environmental impact. Moreover, this technology requires the smallest operating areas and does not depend on climatic conditions. At the same time, mechanical dewatering has some disadvantages relative to other processes: the need for great technological infrastructure and the reagents usage, as well as high capital and operating costs.

The lowest total points (0.479) was determined for solar drying. It is link with high depending on climate conditions, as well as the lack of process automation.

In conclusion, one should be guided by the end product proceeded from faecal sludge when making a selection of technologies. It is also worth considering local climatic conditions, on-site installation features, capital and operating costs. The accumulation place features of faecal sludge also important: FS from the septic tank has a higher humidity, while FS from the pit latrine has high solids content. In any case taking into account all the priority factors, it is possible to select the optimal technology for a specific area taking into account environmental, economic and technological features. 


\section{References}

1. M. Cacanoski, Small-scale wastewater and faecal sludges treatment and management in low-income rural and peri-urban communities in developing countries (IRC International Water and Sanitation Centre, Hague, 2003)

2. J.T. Radford, S. Sugden, Water SA J. 40, 183-188 (2014)

3. H. Harada, L. Strande, S. Fujii, Challenges and Opportunities of Faecal Sludge Management for Global Sanitation (Towards Future Earth: Challenges and Progress of Global Environmental Studies. Kaisei Publishing, 2016)

4. I. Blackett, P. Hawkins, FSM Innovation Case Studies - Case Studies on the Business, Policy and Technology of Faecal Sludge Management (second edition) (Bill \& Melinda Gates Foundation, USA, 2017)

5. K. Ross, K. Abeysuriya, N. Mikhailovich, C. Mitchell, Governance for decentralized sanitation: Global Practice Scan (Institute for Sustainable Futures, ADRAS, 2014)

6. Faecal sludge and septage management - An orientation module (Part A: learning notes) (NIUA, India, 2017)

7. K. Tayler, Faecal Sludge and Septage Treatment - A guide for Low and Middle Income Countries (Practical Action Publishing Ltd, UK, 2018)

8. Standard Operating Procedure for Fecal Sludge Management for Municipalities in Gujarat (CEPT University, 2015)

9. T.L. Saaty, The Analytic Hierarchy Process (McGraw-Hill, New York, 1980)

10. A. Gueye, M. Mbéguéré, S. Niang, C. Diop, L. Strande, Ecol. Eng. J., 94, 617-621 (2016)

11. E. Tilley, L. Ulrich, C. Lüthi, Ph. Reymond, C. Zurbrügg, Compendium of Sanitation Systems and Technologies. 2nd Revised Edition (Eawag, Switzerland, 2014)

12. Implementer's guide to lime stabilisation for septage management in the Philippines (USAID, Philippines, 2015)

13. J. Nikiema, O. Cofie, R. Impraim, Technological options for safe resource recovery from fecal sludge (IWMI, CGIAR, WLE, 2014)

14. E.H.M. Sonko, M. Mbéguéré, C. Diop, S. Niang and L. Strande, J. of W. San. and Hyg. for Dev., 4, 633-641 (2014)

15. A.M. Muspratt, T. Nakato, C. Niwagaba, H. Dione, J. Kang, L. Stupin, J. Regulinski, M. Mbéguéré, L. Strande, J. of W., San. and Hyg. for Dev., 4, 223-230 (2014)

16. http://www.wendewolf.com/klssystem.php?lang=en

17. https://www.huber.de

18. M. Gold, P. Dayer, M.C.A. Sene Faye, G. Clair, A. Seck, S. Niang, E. Morgenroth, L. Strande, Env. Tech. J., 37, 2802-2814 (2016)

19. A. Muspratt, A. Miller, Mechanical Dewatering for Fecal Sludge Treatment Applications Process \& Technology Review (30degrees, 2018)

20. A. Arias-Hoyos, J.L. Hernández-Medina, A.F. Castro-Valencia, N.E. Sánchez-Peña, Biot. en el Sect. Agr. Agr. Ed. Esp., 1, 29-39 (2017)

21. https://www.tencategeotube.com/en/technical-info/how-it-works

22. F. Ziebell, M. Gold, J. Matovu, J. Maiteki, C. Niwagaba, L. Strande, Dewatering of faecal sludge with geotextiles: Results from laboratory and bench-scale experiments in Kampala, Uganda (Eawag, Switzerland, 2016)

23. A.A. Larionova, V.V. Filatov, V.N. Zhenzhebir, I.P. Palastina, N.A. Zaitseva, A.I. Kurbatova, L.E. Glagoleva, Ekoloji J., 106, 571-578 (2018) 